\title{
Feito partitura: palavra sonora como gesto poético de educar
}

\author{
Made in score: sounding Word as an educational poetic gesture
}

\section{Dulcimarta Lemos Lino}

Universidade Federal do Rio Grande do Sul - UFRGS - Rio Grande do Sul - Brasil

\section{Sandra Regina Simonis Richter}

Universidade de Santa Cruz do Sul - UNISC - Rio Grande do Sul - Brasil

Resumo: $O$ artigo emerge de inquietações epistemológicas, éticas e políticas em torno da ampla tendência de desconsiderar na educação de bebês e crianças pequenas o fenômeno do corpo sensível como fonte primeira de sentidos e significados que nos instalam no mundo. Projeto educativo que objetiva fazer da palavra sonora força de utilidade produtiva em detrimento de sua potência de partitura, aquela que cotidianamente aprende a ser-com no ato de com-partilhar as experiências fundamentais da vida. Como resistência, o texto reivindica maior atenção educativa à dimensão poética de linguagem ao destacar a palavra sonora como gesto que habita o corpo para ressoar sentidos e produzir modos de co-existir no mundo. A aproximação fenomenológica entre música e artes, como indivisibilidade do gesto poético de tocar a educação, desde a filosofia, permite compreender a palavra sonora como narrativa lúdica de movimento que ocupa espaço e solicita tempo para reter a dimensão musical da linguagem feito partitura. Aqui, o gesto poético da palavra sonora toca a pele de crianças e adultos para materializar a linguagem: suas feituras. Potência humana de pensamento constitutiva de mundanos trajetos compartilhados por constituírem narrativas que acolhem o gesto lúdico de fazer soar e ressoar a palavra no fascínio e na fabulação dos encontros.

Palavras-chave: Palavra Sonora; Gesto Poético; Música Tradicional da Infância; Experiência de Linguagem.

Abstract: The paper emerges from epistemological, ethical and political uneasiness and concerns on the tendency to disregard the sensitive body as fundamental source of senses and meanings that set us in the world during babies' and early childhood education. This educational project that seeks to make the sounding word as a productive force at the expense of its score potency. A potency that learn everyday to be-with in the act of sharing fundamental life experiences. As resistance, the paper claims more attention to the poetic dimension of language highlighting the sounding word as a gesture that inhabits the body to resound sense and to make modes of coexist in the world. Here, the sounding word's poetic gesture of touching education, from a philosophical standpoint, allows to understand the sounding word as ludic narrative of movement that occupy space and demands time to retain de musical dimension of language made into score. We argue that the sounding word's poetic gesture touches children and adults' skin in order to materialize language. Human thought potency constituent of shared mundane trajectories because they make language that welcome the ludic gesture of making sound the word amidst the fascination and fabulation of encounters.

Keywords: Sounding Word. Poetic Gesture. Childhood's Traditional Music. Language Experience. 


\section{Outra espécie de silêncio: uma palavra deita em meus ouvidos e morre no coração.}

Maria Raquel da Silva Stolf (2011, p. 270)

Para reivindicarmos maior atenção à dimensão poética de linguagem na interação educativa entre crianças e adultos, o artigo destaca a relevância da palavra sonora como gesto que habita o corpo para ressoar sentidos e produzir modos de conviver no mundo comum. Nessa intenção, nos detemos na dimensão musical da linguagem desde uma aproximação entre inquietações que emergem de nossos estudos em torno da educação das infâncias e da formação inicial e continuada de docentes da Educação Básica.

As inquietações que nos mobilizam escrever dizem respeito não apenas às conquistas e constatações de nossas pesquisas no campo educacional das artes articuladas à longa experiência na formação pedagógica de professores para a Educação Infantil e anos iniciais do Ensino Fundamental, mas à compreensão de estarmos diante de um projeto epistemológico e educativo do capitalismo atual com objetivos globais bem determinados por um paradigma de inovação que ultrapassa a digitalização da sociedade do conhecimento e da informação. Não estamos apenas ante a mercantilização do conhecimento ${ }^{1}$, mas frente à priorização ou o controle de determinadas capacidades e experiências de linguagem que visam uma única meta econômica: fazer do pensamento e do conhecimento forças de utilidade produtiva em detrimento de sua potência reflexiva e autônoma.

\footnotetext{
1 Hannah Arendt (2014) destaca a distinção entre duas atividades inteiramente diferentes, pensar e conhecer por constituíerm duas preocupações distintas, o sentido, para a primeira, e a cognição para a segunda. Assim, para a filósofa, pensamento e cognição não são sinônimos, pois "fonte das obras de arte, o pensamento (...) não tem outro fim ou propósito além de si mesmo, e não chega sequer a produzir resultados". Já a cognição, fonte da ciência, "sempre persegue um fim definido, que pode ser determinado tanto por considerações práticas como pela 'mera curiosidade'; mas uma vez atingido esse fim, o processo cognitivo termina" (ARENDT, 2014, p. 212).
}

Aqui, partilhamos com Marina Garcès (2017, p. 71), que se "as humanidades estejam hoje em transição significa que o sentido do humano está em disputa. Não é uma querela ociosa nem gratuita. Nela se joga o interesse de todos contra os interesses do capitalismo atual". Talvez, a tarefa educacional por vir esteja no ato de resistência ao desencantamento educacional que vivemos diante da crescente aridez utópica que assola a convivência e faz a palavra hoje se despir da dimensão poética por não carregar sonhos e utopias até um mundo diferente (COUTO, 2011).

Assumir como ponto de partida nossa inquietude sobre a linguagem e na linguagem, provocada pela experiência mesma de linguagem, destaca Jorge Larrosa (2001, p. 68), "não é o mesmo que partir de nossos conhecimentos sobre a linguagem".

Quando partimos do que sabemos sobre a linguagem só ouvimos o que já entendemos. Mas, na experiência da linguagem, e talvez por isso seja inquietante, o que permanece comprometido e suspenso é precisamente o que já sabemos, o que já entendemos, o que já ouvimos, o que se deixa capturar sem dificuldade pela linguagem quando falamos dela (dos fatos, dos sucessos, das coisas, dos problemas, de nós mesmos, de nossa linguagem) precisamente porque não prestamos atenção ao ser da linguagem mesma que fala (LARROSA, 2001, p. 69).

O que sabemos e/ou podemos entender do fenômeno da relação de alteridade na experiência de linguagem entre bebês, crianças e adultos, seja na ação pedagógica, na formação docente ou no campo de estudos da pedagogia, não alcança a complexidade de produção de diferença no mundo comum. Aquela que permite Mia Couto (2011, p. 13) afirmar que "o que fez a espécie humana sobreviver não foi apenas a inteligência, mas a nossa capacidade de produzir diversidade", isto é, nossa humana condição de produtores e cantadores de histórias.

Desde o ponto de vista ético, estético e político, o que está em jogo é o sentido educacional da dignidade e da liberdade humanas em sua condição de ser elaborado de maneira recíproca e 
compartilhada. Tal condição inquietante impõe estudar e escrever para interrogar como resistir à armadilha educacional de submeter bebês, crianças e

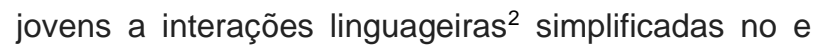
com o mundo, a experiências mundanas restritas dadas pela desconsideração epistemológica do corpo sensível como fonte primeira de sentidos e significados que nos instalam no mundo (MERLEAUPONTY, 1999). Resistência que nos faz interrogar, com Jean-Luc Nancy (2019, p. 96), "como nos relacionamos com o mundo quando no fundo estamos completamente divididos entre o inteligível e o sensível?"

Com os poetas, os quais "trazem outras luzes a respeito do humano" (BACHELARD, 1988, p. 120), podemos afirmar que na infância a palavra não precisa significar, é só entoar; "porque significar limita a imaginação" (BARROS, 2015, p.4). É, talvez, essa inutilidade ou inoperatividade (AGAMBEN, 2010) da dimensão brincante da experiência linguageira que movimenta a coexistência pela escuta atentamente distraída ao mundo que em nós vem se sentir. Para ler o segredo do mundo tornar-se mundo para nós, sublinha Merleau-Ponty (1999), temos que buscá-lo em nosso encontro com a realidade sensível e comum que nos constitui, aquela que desde sempre estamos imersos, e empregar "as palavras para dizer essa ligação pré-lógica e não conforme sua significação preestabelecida" (MERLEAU-PONTY, 1999, p. 47).

A fenomenologia de Merleau-Ponty aponta o que Jean-Luc Nancy (2003, p. 66) sublinha ao escrever que "simplesmente, não há procedência do sentido: ele se apresenta, isso é tudo". Antes de todo sentido, "nós somos o sentido" (NANCY, 2003, p. 68) pois é nossa existência que se apresenta como sentido na simultaneidade que nos apresentamos a nós mesmos. Esse "nós" do sentido, que é em si o sentido, não procede como reconhecimento nem como identificação, mas como exposição: somos

2 O termo linguageiro é utilizado, com MerleauPonty (1991, p. 94), para afirmar que há uma significação "linguageira" da linguagem que não se prende ao "penso" cartesiano, mas ao "posso" do corpo operante no e com o mundo. expostos (NANCY, 2003). Ambos os filósofos nos convidam a assumir que o mundo "a cada instante se faz em nós" (MERLEAU-PONTY, 2011, p. 440). Nessa compreensão, embalada no vínculo primeiro dos brinquedos musicais, a criança tem no corpo da mãe o gesto poético que abraça, amarra, ata, liga e vincula para constituir sua língua materna na possibilidade mesma de entrar em linguagem tanto pela experiência de ressonância da sonoridade das palavras no seu corpo quanto pela abertura ao sentido de coexistir. Essa compreensão aponta para a ação de brincar como a língua do devir humano, primeiro idioma da infância, este "idioma do caos" no qual "todas as línguas eram nossas. Dito de outro modo, todos nós somos impossíveis tradutores de sonhos. Na verdade, os sonhos falam em nós o que nenhuma palavra sabe dizer" (COUTO, 2011, p. 12).

Nesta escrita aproximamos estudos fenomenológicos por nós realizados no campo da música e das artes na educação de bebês e crianças para demarcar a potência de pensamento que emerge do gesto poético de tocar o mundo para produzi-lo na convivência. A interlocução que realizamos com as artes, a filosofia e a educação permite tanto abordarmos a dimensão poética da linguagem ao destacarmos a palavra sonora como dimensão musical da linguagem quanto interrogar as marcas gráficas instituídas como idiomas que, mais que expressão das culturas e das sociedades, tem impresso separações e territórios de poder como legitimação do controle de determinados modos de produzir linguagem.

Encontramos sustentação para nossos estudos e interlocuções na intencionalidade de dissolução do dogma do signo linguístico como unidade expressiva entre forma e conteúdo. Com Giorgio Agamben (1999) resistimos à significação representativa da linguagem e apostamos no ato inaugural do gesto poético da palavra sonora que emerge entre nós, na coexistência, pois

só a palavra nos põe em contacto com as coisas mudas. A natureza e os animais são desde logo prisioneiros de uma língua, falam e respondem a signos, mesmo quando se calam; só o homem consegue interromper, na palavra, a língua infinita da natureza e 
colocar-se por um instante diante das coisas mudas (AGAMBEN, 1999, p.112)

Para o filósofo italiano, se os animais não têm a capacidade de entrar na linguagem, pois o gato nasce e morre miando; o cachorro nasce e morre latindo, os humanos "deve[m] constituir-se como sujeito de linguagem, deve[m] dizer eu" (AGAMBEN, 2011, p.71), pois "não nascemos com a linguagem, nascemos com a capacidade de entrar em linguagem" (AGAMBEN, 2011, p. 23). Aqui, a palavra sonora como gesto poético de linguagem irrompe e invade exaustiva e sistematicamente a coexistência ao promover abertura à multiplicidade infinita de sentidos mundanos: potência de pensamento.

Afirmar a relevância educacional de prestarmos atenção pedagógica à experiência de linguagem como força poética que emana da palavra sonora como gesto no mundo é sublinhar a relevância de uma docência comprometida com "ser junto, sercom" (NANCY, 2015, p. 171). Nessa compreensão, antes de ser palavra, língua, voz e significação, linguagem é

a extensão e a simultaneidade do "com" como maior potência de um corpo, sua propriedade de tocar a outro corpo (de tocar-se), que nada mais é que sua de-finição de corpo. Finaliza cessa e se cumpre, com um mesmo gesto aí onde é-com (NANCY, 2006, p. 108, grifos do autor).

Mas, também é sublinhar a palavra sonora que, feito partitura, desconhece trajetos ou significados previamente determinados para emergir como processo de instauração de sentidos pela possibilidade ou impossibilidade de desdobramentos acústicos e/ou sonoros que insinua a ativação de uma presença (a qual se abre ao seu próprio sentido). Supõe interrogar como bebês e crianças pequenas soam e ressoam - "barulham" (LINO, 2008) movidas pelo desejo de escutar o mundo escutandose.

Música tradicional da infância: cantigas de Makuru e brincos
Ao destacarmos a dimensão musical da linguagem como narrativas lúdicas que emergem do gesto poético da palavra sonora, afirmamos que a Música Tradicional da Infância constitui potência formadora indispensável aos bebês e crianças por ensinar o corpo a tocar a pele da palavra sonora. $\mathrm{O}$ intenso estudo de Lydia Hortélio (1982) no campo da Música Tradicional da Infância contribui para afirmarmos que a música existe no corpo brincante regida pelas palavras que Ihe impõem um caráter, uma cor, uma dicção, uma afinação, um tempo de existir no brincar. Hortélio e Reys (2013) nomeiam brinquedo tanto o fenômeno cultural quanto sua forma, sem separações. Ou seja, para que um brinquedo aconteça é necessário a íntima interdependência entre palavra, ritmo, movimento e o outro. Por e nessa simultaneidade, brinquedo é ação, movimento. É verbo: brincar. A educadora e musicista alerta que o brinquedo é indivisível, sendo cada uma de suas partes condição insubstituível para o acontecimento do brincar. Nessa concepção, o brinquedo "é um organismo vivo, a manifestação da inteireza, da inteligência com 0 corpo, da sensibilidade e da cidadania" (HORTÉLIO, REYS, 2013, p.24).

Ao fazerem parte das produções coletivas e anônimas da cultura e da música popular brasileiras, edificadas na memória de gerações, a infinita complexidade e pluralidade de brinquedos brasileiros se apresenta em miríades possíveis de narrativas lúdicas que recontam nossa própria história (HORTÉLIO, 2020) pela condição de presentificação da ação brincante acontecer no ato de fazer-se-com os outros. Assim, é de modo lúdico que crianças e adultos se entregam às feituras do gesto poético, isto é, a esses fazeres com-partilhados de "produção inoperante" ou "poética da inoperosidade" (AGAMBEN, 2007; 2018), os quais promovem abertura à coprodução de sentidos que os situam na existência mundana. Tal partilha tem como referência a mundanidade (ARENDT, 2014), a qual responde à condição humana de produção ficcional - ou lúdica de mundos pela produção de obras duráveis ou 
fabricações $^{3}$ - feituras - que instauram uma temporalidade que permite o reconhecimento de vidas singulares, e não apenas da humanidade. A potência poética das produções ou feituras mundanas indica simultaneidades heterofônicas indivisíveis que emergem entre mundano e humano, entre funcional e artístico; entre sensível e inteligível; entre sagrado e profano, entre folclórico e popular; entre partitura e oralidade; entre músicas destinadas ao público infantil e ao público adulto.

Por promoverem uma travessia aventureira, os brinquedos possibilitam que crianças e adultos entrem e saiam da fabulação e da ação de imaginar como experiência de abertura à linguagem sem fronteiras (BACHELARD, 1988). Esse deslocamento entre real e ficcional é provocado pelas convicções que a ação lúdica retira de si mesma, "sem ser atormentada por censuras" (BACHELARD, 1988, p. 154). Para o corpo em movimento no e com o mundo, real e ficcional não são antagônicos. Na expressão bachelardiana, são "complementares bem feitos" em seu poder de afetarem com a mesma intensidade e permitirem ao corpo sensível operante (MERLEAUPONTY, 1999) aprender a ser afetado de muitos modos. Nessa dinâmica tão lúdica quanto lúcida, o corpo encarnado no e pelo mundo aprende a produzir diferenças.

No ato de movimentar palavras sonoras que cabem na boca e no jeito de ser, de andar, de cantar e de olhar de cada um e de todos, em distintos tempos e espaços, as crianças gradualmente vão constituindo percursos de linguagem, isto é, vão inaugurando formas de pensar": ato revolucionário

${ }^{3}$ O mundo, em Hannah Arendt (2014), mais que comunidade humana, é artíficio ou obra do homo faber. $O$ mundo a que se refere a filósofa não corresponde ao planeta Terra, nem mesmo à esfera pública por mera contraposição ao espaço privado por constituir criação do artifício humano, um lar imortal erigido pela obra humana para abrigar sua existência mortal, um legado do qual os novos que nele chegam devem ser iniciados pela educação.

${ }_{4}$ Para Hannah Arendt (2003, p. 40-41), pensar é criar, é imaginar possibilidades, é engendrar pensamento no pensar, diferente dos processos cognitivos como "a dedução, a indução e a elaboração de conclusões, cujas regras lógicas de por ser ato que implica "reaprender a ver o mundo" (MERLEAU-PONTY, 1999) ao trazê-lo para uma instância anterior, isto é, a imediata experiência do corpo no mundo, aquela que alicerça a singularidade de minha relação com a pluralidade dos outros.

Sem pretendermos pontuar este ou aquele brinquedo, mas afirmarmos sua multidimensionalidade, consideramos importante destacar dois gêneros poético-musicais que integram o cancioneiro brasileiro e instauram palavras sonoras que marcam feituras do gesto poético musical. Aparentemente antagônicas, as Cantigas de Makuru e os Brincos carregam possibilidades de encontros que o pensamento pedagógico deveria se ocupar (HORTÉLIO, 2013, p.30) pela potência produtora de si e de mundos que nos situam em nossa historicidade.

As Cantigas de Makuru são canções de ninar brasileiras dos povos indígenas que se relacionam à ação de fazer adormecer as crianças, não como um relaxamento ou uma paralisação do corpo, mas como o tempo e o espaço disponibilizados para que elas possam voar até outra aldeia, visitar terras distantes, caminhar nas trilhas do passado e abrir-se ao sonho, ao sagrado (MACHADO, 2017, p.132), tempo de retidão. Recolhidas por Rodrigues (1890), as Cantigas de Makuru constituem uma das primeiras manifestações orais da região amazônica, também pertencentes ao acervo de Mário de Andrade (1929). Com a função de religar o humano a uma totalidade orgânica comunitária, espacial e temporal (o próprio corpo), as Cantigas de Makuru utilizam como palavras cantadas as expressões e verbos: estar livre, viajar, voar, ir até, caminhar, dormir, sonhar (MACHADO, 2017, p.135). Nesses sonhos, a criança também pode receber cantos das divindades para serem compartilhados.

No livro Poranduba Amazonense, Rodrigues (1860) nos apresenta onze Cantigas de Makuru, das quais destacamos abaixo o texto de uma delas: YACURUTU.

Yacurutu rep uru ne repocê - Yacurutu tu emprestas teu sono

não-contradição e coerência interna podem ser aprendidas e aplicadas”. 
Taina pitanga u quire arama - Filho pequenino dormir para

O canto do Yacurutu, por fazer parte das canções de ninar brasileiras originárias, necessita da lentidão, da monotonia, da repetição infindável de versos. Música que reverbera o convite para entrar no movimento flutuante do voo. Aqui, pela forma sonora de conjugar o excesso temporal da palavra cantada demorada (aquela que de-mora ou que habita o tempo), há uma ex-posição à lentidão, à espera de um sentido que puxa todo o corpo para tocar sua escuta. Machado $(2017,132)$ permite compreender que a palavra Makuru designa o berço do índio brasileiro, um típico cesto de cipó coberto de algodão e suspenso por uma corda ao caibro da casa que se destina a ser 0 leito da criança pequena. Diferentemente do berço português, que se apoia fixamente no piso, "o Makuru é suspenso, pendular, aéreo. (...) prevê o uso da força dos membros de locomoção e o impulso dado pelas pernas da criança para o embalo" (MACHADO, 2017, p.134).

Se o Makuru se dispõe a uma altura ideal para que a criança nele colocada possa tocar com os pés o chão da terra e exercer a autonomia do corpo para se embalar, o berço português prevê a contenção do corpo da criança ao movimento e ao toque da terra. Na imitação do pássaro, as Cantigas de Makuru expressam a busca pela vitalidade no repouso do organismo e na mobilidade sagrada, inspiradas na natureza, na observação e na escuta. A partir da colonização europeia, as cantigas de ninar brasileiras se transformaram em Canções de Berço que, entoadas pelas mães, amas de leite, mães pretas, babás e babysitters pretenderam fixar o berço acima da terra pela imobilidade diária que impõe à criança permanecer parada. A conjugação entre espera (adulto) e resistência (criança), acaba por criar uma pulsação que flui e estanca repetidamente, combinando relações sutis de poder entre o embalador e o embalado. Tal acordo tem no corpo enredado a combinação firmada entre palavra, ritmo, movimento e o outro a possibilidade disruptiva de os colocar em atrito. Também nomeadas berceuses ou acalantos, essas Canções de Berço têm no texto a marca do medo, do horror, da ameaça do Papão português (MACHADO, 2017, p, 131-138).

Mário de Andrade (1929), em suas andanças de etnógrafo pela Amazônia, viveu a canção de ninar como fenômeno cultural e nos conta a intensidade do estremecimento que lhe causou ouvir uma indígena entoar para o filho, fluentemente junto de versos de sua língua mãe, incisos melódicos de um 'Te Deum'. Este gênero musical sacro, que na liturgia romana encerrava as matinas aos domingos e datas solenes, usado para cumprir a antiga tradição da oração noturna, feito partitura, é "resumo vivo da alma coletiva, sua mais ingênua forma de revelação e contato" (MEIRELES, 1941 apud VIEIRA, 2013, p. 80). O espanto e a admiração de Andrade podem ser compreendidos pela profundidade da palavra sonora com-partilhada entre mundo indígena e mundo mestiço, a qual apresenta ou expõe o esforço em lhes dar um lugar na cultura como "intenção e invenção do adulto que transmite na linguagem o que crê adequado à compreensão e ao gosto de seu público" (MEIRELES, 1951 apud VIEIRA, 2013, p.114).

A densidade da contribuição da música tradicional da infância brasileira encontra-se na vivência coletiva e comunitária, a qual permite aproximar "os laços de uma definida e sustentada tradição comum" (MEIRELES, 1941 apud VIEIRA, 2013, p.84) pela "palavra que embala e é na palavra ou no espaço da palavra que se constrói o trajeto em que a criança pode sentir que algo volta" (HORTÉLIO; REYS, 2019, p.26), proporcionando-lhe satisfação, acolhimento, assistência e conforto. O cuidado com essas palavras, sua entonação, afinação, repetição e - modo de escutá-las quando murmuramos, resmungamos, falamos, cantamos, ou silenciamos, e os ritmos que lhes incorporamos é primordial para as feituras do gesto poético por permitirem a inauguração de experiências de estar em linguagem na primeira infância. Aqui, o importante é participar brincando e encontrar-se no outro, instante no qual a "união do corpo e da alma, constitui a base da criação de uma verdadeira arte de viver" (MACHADO, 2017, p.16). 
Ao fazer parte da diversidade de brinquedos brasileiros, os Brincos são um tipo de parlenda no qual a palavra, o ritmo, o movimento e o outro convidam o bebê à diversão e à alegria (MELLO, 1985). A palavra sonora é declamada sem o canto, formando uma rima ou um dito que só quer vincular ${ }^{5}$. De modo geral são realizados com os bebês no colo dos adultos, sempre acompanhados de gestualidades que tocam seu corpo e Ihes convidam ao movimento. Os bebês são envolvidos pelas entonações rítmicas das palavras que, no acelerar, trotar, galopar, ralentar ou paralisar, causam surpresa e admiração. tradicional brinco Upa cavalinho é o mais conhecido ao longo de diferentes civilizações. Nos Brincos a ação, a energia, o ritmo e a tonicidade são características emergentes. Abaixo, apresentamos Ao Passo, um dos Brincos que aprendemos com nossas avós:

Ao passo, ao passo, ao passo

Ao trote, ao trote, ao trote

Ao galope, ao galope ao galope

Sentado de mãos dadas no colo do adulto, o bebê começa no ritmo lento do passo, dobra o tempo ao declamar o trote e sai acelerando com rapidez quando chega no galope. Ao experimentar a aceleração do brinquedo na palavra sonora que corre, que ralenta ou que é interrompida, o bebê vive as nuanças e os contrastes instalados na língua. A palavra ocupa um espaço, solicita um tempo e impõem um ritmo para acolher o corpo do outro no mundo, coexistência do viver.

As Cantigas de Makuru e os Brincos acima descritos apresentam um recorte na diversidade das narrativas lúdicas inscritas no repertório dos brinquedos infantis. Essa prolongação do passado no presente mantém a palavra sonora como gesto poético que movimenta a potência das feituras do corpo. Agamben (2018), ao abordar o ato poético como ato de resistência, sublinha sua relação constitutiva com a liberação de uma potência. A partir da intenção de dar continuidade e prosseguimento ao

5 O termo "vínculo", que especifica a brincadeira, tem sua origem derivada de brinco, do latim vincùlum - liame, laço, atadura. pensamento de Deleuze ${ }^{6}$, Agamben (2018) distanciase do conceito de criação da obra de arte $^{7}$ para destacar que "a potência que o ato de criação libera, deve ser uma potência interna ao próprio ato" (AGAMBEN, 2018, p.62). Para tanto, o filósofo opta por substituir criação pelo termo poético para sublinhar seu sentido de poiein, de "produzir" e negar a representação corrente de ato de criação como simples trânsito da potência ao ato.

Se a criação fosse apenas potência-de, que não pode senão resvalar cegamente para o ato, a arte decairia para a execução, que procede com falsa desenvoltura em direção à forma consumada por ter removido a resistência da potência-de-não (AGAMBEN, 2018, 67-68).

. Porém, Agamben (2018, p. 66) destaca que a potência envolve dois princípios intimamente unidos os quais permitem acolher o ato poético "como um campo de forças tensionado entre potência e impotência, poder e poder-não, agir e resistir". A inoperosidade do gesto poético marca presença, expõe e sustenta a forma que na repetição do exercício poético pode ensinar ao corpo outros modos de ser como abertura a sua potência de não ser, sua própria impotência ${ }^{8}$. Nessa compreensão, com Agamben (2018, p. 73) podemos afirmar que "a grande poesia não diz apenas aquilo que diz, mas também o fato de que está dizendo, a potência e a impotência de dizê-lo", como suspensão e exposição da potência da língua. Aqui, não há uma potência de não cantar que preceda o ato de cantar, mas uma

\footnotetext{
${ }^{6}$ Agamben (2018) retoma a conferência "O ato de criação" que Gilles Deleuze proferiu em Paris em março de 1987, na qual definia o ato de criação como um "ato de resistência".

${ }^{7}$ Agamben, ao preferir "ato poético" em detrimento de "criação" manifesta seu desconforto com o generalizado emprego do termo criação em relação às práticas artísticas pelo deslocamento de criação divina (creare ex nihilo) para o fazer humano (facere de materia) como transposição do paradigma da criação de Deus para a atividade do artista (AGAMBEN, 2018, p.61).

${ }^{8}$ Em Agamben (2018, p. 72), "a potência-de-não não é outra potência ao lado da potência-de-: é sua inoperosidade, o que resulta da desativação do esquema potência/ato. Ou seja, existe um nexo essencial entre potência-de-não e inoperosidade".
} 
resistência que o impede de esgotar-se simplesmente no ato de cantar como mera execução do canto.

É na resistência da potência-de-não que a potência expõe a possibilidade de formar e exibir sua resistência interna, aquela que a impede de se esgotar na mera passagem ao ato pela exigência de voltar-se a si mesma, ou seja, fazer o canto do canto, "tornar possível o pensamento do pensamento, a pintura da pintura, a poesia da poesia" (AGAMBEN, 2018, p. 75). Essa suspensão da passagem ao ato, a qual torna a potência inoperante, implica considerar que a música (ou a pintura, ou a poesia, ou o pensamento) não é o objeto do sujeito que canta ou que toca um instrumento, assim como a pintura não é o objeto do sujeito que pinta ou o pensamento não é o objeto do sujeito pensante. Ao contrário, a potência da poesia é expor e suspender a língua como operação na linguagem que desativa e torna inoperantes funções comunicativas e informativas ao promover abertura para outras possibilidades de estar em linguagem. Abertura que exige disponibilidade para outras sensibilidades habitarem a linguagem, outras poéticas que permitam sermos o outro, não para conceituá-lo ou abstraí-lo, mas para acolhê-lo como o outro em nós.

\section{Gesto poético de linguagem e palavra}

\section{sonora}

Com Agamben (2010, p. 54) afirmamos que gesto é aquilo que se mostra em toda sua potência por não obedecer a um fim, mas por constituir "movimento que tem em si mesmo seu fim (por exemplo, a dança ${ }^{9}$ como dimensão estética)". Sem pretender uma significação ou representação, o gesto mostra o que não pode ser dito. O que permanece inexpressivo. Para situá-lo na ordem do profano e da inoperatividade, Agamben (2010) parte de uma

9 Agamben (2010, p. 54 grifos do autor) destaca que se a dança é gesto, "é, precisamente, porque não consiste em outra coisa que suportar e exibir o caráter de meios dos movimentos corporais. 0 gesto é a exibição de uma mediação, o fazer visível um meio como tal. Faz aparecer o-ser-emum-meio do homem e, desta forma, Ihe abre à dimensão ética". observação de Varrão ${ }^{10}$ para com ele tanto inscrever o gesto na esfera da ação como para o distinguir claramente do agir e do fazer. "O que caracteriza o gesto é que, nele, não se produz nem se age, mas se assume e suporta" (AGAMBEN, 2010, p. 53). A afirmação aponta o gesto como ato de assumir e posicionar uma ação, como abertura própria aos comportamentos, hábitos ou crenças (ethos) que simultaneamente - e por excelência - especificam e distinguem movimentos corporais nas interações humanas. Uma ação que suporta o instante vivido e movimenta o cotidiano - e não o extraordinário como matéria-prima constituinte da experiência que cada geração transmite a geração seguinte (AGAMBEN, 2011, p.9).

Nessa investida lúdica, o gesto promove a integração entre sensível e inteligível, entre imaginação e razão, potência que pode produzir e refazer o mundo no ato de interpretar e transfigurá-lo em sentidos experimentados no coletivo. A concepção de experiência remete aos modos como estabelecemos relações com os outros, com o mundo e conosco mesmos, os quais não separam fazer e pensar, antes inauguram sentidos que os tornam inteligíveis na convivência (RICHTER; BERLE, 2015).

$$
\text { Agamben (1999; 2018) considera a }
$$
inoperatividade como potência constitutiva da humanidade, um gesto de possibilitar outro exercício da palavra, um novo modo de estar em linguagem. Tal operação inativa contempla e acolhe o nosso poder, ou aquilo que podemos ou não podemos fazer. Aqui, como na experiência poética de linguagem, potência e impotência coexistem. Para explicitar sua concepção de "operação inoperativa", a qual permite apontar que o significado político da arte está em ser uma operação "que torna inoperativo e que contempla os sentidos e os gestos habituais dos homens e que, desta forma, os abre a um novo possível uso" (AGAMBEN, 2007, p. 49), o filósofo exemplifica com a interrogação pelo sentido da poesia.

10 Marco Terêncio Varrão (em latim Marcus Terentius Varro), filósofo que viveu na península por volta do séc. I a.C. 
O que é, aliás, um poema, senão aquela operação linguística que consiste em tornar a língua inoperativa, em desactivar as suas funções comunicativas e informativas, para a abrir a um novo possível uso? Ou seja, a poesia é, nos termos de Espinosa, uma contemplação da língua que a traz de volta para o seu poder de dizer. Assim, a poesia de Mandelstam é uma contemplação da língua russa, os Cantos de Leopardi são uma contemplação da língua italiana, as lluminações de Rimbaud uma contemplação da língua francesa, os hinos de Hölderlin e os poemas de Ingeborg Bachmann uma contemplação da língua alemã, etc. Mas, em todo o caso, trata- se de uma operação que ocorre na língua, que actua sobre o poder de dizer. E o sujeito poético é não o indivíduo que escreveu os poemas, mas o sujeito que se produz na altura em que a língua foi tornada inoperativa, e passou a ser, nele e para ele, puramente dizível (AGAMBEM, 2007, p.48).

Mia Couto (2011, p. 11) permite compreender essa língua tornada inoperativa, essa "poética da inoperosidade" (AGAMBEN, 2018) ou esse idioma sem regra no qual "já não sabe se fala, se canta, se reza", ao lembrar que "todos nós aspiramos regressar a essa condição em que estivemos tão fora de um idioma que todas as línguas eram nossas" (COUTO, 2011, p.12). Na infância, todos nós experimentamos este primeiro idioma como um "idioma do caos", esse "momento divino em que a nossa vida podia ser todas as vidas e o mundo ainda esperava por um destino" (COUTO, 2011, p.12). Para o escritor moçambicano, é essa operação que mobiliza o ato de escrever em qualquer língua ou gênero literário como "vocação divina da palavra que não apenas nomeia mas que inventa e produz encantamento" (COUTO, 2011, p.14). Aqui, a língua se apresenta plural em suas possibilidades e impossibilidades tornando difícil ser contida em normas ou códigos, pois algo escapa e ultrapassa a comunicação. A língua "transcende essa dimensão funcional. Às vezes, as línguas fazem-nos ser" (COUTO, 2011, p.13).

Com Merleau-Ponty (1991, p. 104) podemos afirmar que "é no próprio exercício da palavra que aprendo a compreender" (MERLEAU-PONTY, 1991, p. 104). A compreensão emerge da experiência intercorporal de linguagem, na qual coisas são ditas ou mostradas "por um ser que tem corpo e linguagem a um ser que tem corpo e linguagem, cada um dos dois puxando o outro por fios invisíveis [...] fazendo o outro falar, fazendo-o pensar, fazendo-o tornar-se aquilo, que é, e que nunca teria sido sozinho" (MERLEAU-PONTY, 1991, p. 19). Tal afirmação nos faz compreender que a constituição linguageira da singularidade - esse "nos fazer ser" pela língua emerge em extensão e simultaneidade do "ser-com", a qual Nancy (2006, p. 19) anuncia ao afirmar que "o ser não pode ser mais que sendo-os-uns-com-osoutros, circulando no com e como com dessa coexistência singularmente plural" (NANCY, 2006, p.19, grifos do autor).

Ambos os filósofos afirmam a condição de singularidade à exposição ao nós", de um "nós" que não é um sujeito coletivo mas a dimensão comum de singularidades no e com o mundo. Se na fenomelogia merleau-pontyana "nós"11 não é um pronome pessoal nem um sujeito plural, mas o sentido do comum que ultrapassa a relação entre pessoas ou a comunicação entre consciências singulares, em Nancy (2006, p. 18, grifo do autor) "não há sentido se o sentido não se compartilha, e isto não porque tenha uma significação, primeira ou última, que todos os seres tenham em comum, mas porque o sentido mesmo é a participação do ser".

Todos os bebês que chegam têm a possibilidade de sonorizar no prisma extenso de todas as línguas. Segundo Fridmann (1988), Akoschky (2016) e Lino (2008), o som da respiração dos bebês, seus choros, balbucios, gorjeios, gritos, conversas, resmungos e cantos, habitam todas as línguas por constituírem vínculo afetivo e rítmico de um corpo que se faz presença imitando, improvisando, escutando e produzindo sentidos para o que vivencia. Porém, o esmagador poder das sonoridades de sua língua mãe, as quais vibram no corpo do bebê desde o ventre, nutrindo-o na acuidade sensível de sua ambígua condição vital de

11 Cabe destacar que na fenomenologia de Merleau-Ponty (1999) não há soma de "eus", mas uma operação de co-implicação de corpos (intercorporalidade ou intersubjetividade) que diz respeito à dimensão comum e anônima da coexistência. 
simultaneidade interna e externa, paulatinamente o fazem adentrar e operar sua língua materna.

Como diz Caetano Veloso (1984), "minha língua, minha pátria". De feto vivo e flutuante que balança e nada nas ondas do líquido amniótico que Ihe aconchega, mas que também faz vibrar afetos, os ritmos e a voz dos cantos de trabalho da mãe, o bebê tem no nascimento seu primeiro gesto sonoro: o choro. Tal ação, ao mesmo tempo humaniza o bebê e o separa para sempre do corpo da mãe ao fazê-lo entrar na língua. Nessa outra sempre viva, celebrada por aquilo que manifesta: cultura, música, arte, pensamento, poder, o choro

é um procedimento de sobrevivência não só físico, ligado à respiração; o choro é o primeiro gesto de som que coloca a criança em um estado de conversação com os outros, e que permitirá, mais tarde, aprender a sua língua materna e diferentes jogos e músicas que esculpem a voz humana falante, dominando o esforço, a respiração, o ritmo, o tempo, definindo uma gama de sons próprios, reconhecendo a dos outros (LOPEZ, 2019, p.19).

Segundo Lopez (2019), este gesto sonoro em estado de conversação com os outros, no e com o mundo, constitui a proteção simbólica da infância. Ao compreendermos que bebês e crianças pequenas são os seres que mais exercitam a produção de sentidos pela ação de brincar, destacamos que cabe aos adultos garantirem o direito à palavra poética como gesto produtor de sentidos; vasos comunicantes que lhes permitem situarem-se e reconhecerem-se um no outro. Ao brincar, começa a nascer a linguagem (LOPEZ, 2019).

Então, se o brincar é a língua do devir humano, último reduto da espontaneidade infantil (HORTÉLIO, 2013), temos que tocar a língua para experimentar e expor maneiras de ser. Modos que implicam gestos poéticos de estar com, que para Nancy (2015, p.173) constituem a "forma e visibilidade da possibilidade do viver junto" por compreender que um gesto

Não é nem um movimento, nem um traçado de uma forma. Um gesto de maneira geral, quero dizer na vida, se poderia dizer que é o acompanhamento de uma intenção, porém que, em si mesmo, permanece estranho a uma intenção (...) O gesto é um dinamismo sensível que precede, que acompanha ou que sucede ao sentido ou a uma significação, porém é sentido sensível (NANCY, 2014, p.31).

Ao se constituir como resistência a toda restrição ligada a qualquer forma de dominação, o gesto, para Nancy (2014) mostra sem designar, oferece sem destinar, propõe sem impor, expõe sem depor. O gesto pode instaurar o reino dos sentidos e sustenta o desejo de encontrar-se no eco de fazer-secom. Sendo da ordem da sensibilidade e do movimento, o gesto vibra ressonâncias e tem na escuta "o som do sentido" (NANCY, 2007). Assim, o gesto comove e inquieta porque materializa a estreita dependência dos dispositivos materiais, simbólicos e afetivos particulares de cada cultura (NANCY, 2014) e de suas partilhas (NANCY, 2016).

$\mathrm{Na}$ tentativa brincante de conjugar o verbo partir, Nancy (2016) nos lembra do sentido de partitura em seu sentido musical como

o caderno sobre o qual se imprime música. Se chama partitura porque a música se escreve no pentagrama, onde anotamos os momentos da melodia, porém também, as partes das diferentes vozes quando temos que interpretar uma composição, ou as partes de diferentes instrumentos em uma orquestra. As palavras dessa família vêm do latim "pars" (a parte) e "partire" que significam dividir, separar. (...) repartir" (NANCY, 2016, p.16).

A palavra partitura contém em si a ideia de dividir, separar, de partir e, simultaneamente, a ideia de compartilhar. O papel divide e formata uma composição, mas a música apenas existe quando entra em ressonância e, pela escuta indizível, é partilhada acusticamente. Logo, são dois em um, sem separações nem oposições. A partitura imprime o gesto de um tempo e um espaço da repetição, do exercício, de escolhas. Implica sempre dividir-se, compartilhar, separar-se de si mesmo. Deixar o gesto sonoro espontâneo que desenha o som para experimentar a necessidade de criar intencionalmente formas convencionadas de fazer música. Partes que definem estilos, instauram memória, ressoam pontos de escuta (NANCY, 2016). Nesse contexto, tocar e/ou escutar a música feita na partitura não significa decodificar a representatividade sintáxica da notação 
musical, mas in-corpo-rar feituras dessa ação de partilha, sempre pública e coletiva.

Sendo parte daqueles que partiram, nos tornamos humanos porque estamos sempre a ponto de partir, certos de que nenhuma chegada é definitiva (NANCY, 2016, p.31). Assumir o risco brincante na aposta da partida é deixarmos o familiar (que por definição já ignoramos no início) para experimentar o novo (às vezes inquietante, provocador), certos de que na separação, somos os dois. Ao fazer-se música, a partitura vive o indizível, deixa o papel para existir na experiência de sentidos. Sempre singular e compartilhada porque ressonância em com-junto. O grifo vem de Nancy (2015, p.173) para significar que esse viver junto incorpora tanto o puro comtato (tocar à pele) quanto o ser com os outros.

Para Nancy (2013), tocar é entrar diretamente em contato com as coisas do mundo. Tal ação estremece e faz-se mover, porque ex-posição aos sentidos. Segundo Nancy, a constituição do mundo se dá "numa exploração de presença na multiplicidade original de sua participação" (NANCY, 2006, p.19) Assim, tocamos para acolher a fruição de um corpo que no gesto poético pode desenhar o som ou apenas deixá-lo partir. Tocar é simultaneamente estar tocante e sentir-se tocado, pois "tocar começa quando os corpos se distanciam e se distinguem um do outro" (NANCY, 2013, p.12). Se tocar exige a ação de entrar diretamente no encontro com as coisas, quando a criança nasce ela

sai do ventre e, por sua vez, torna-se um ventre capaz de engolir e de regurgitar. Com a boca, ela apreende o seio da mãe ou o dedo. Chupar é o primeiro tocar. Como se sabe, a sucção aspira o leite que alimenta. Mas ela também faz mais do que isso: ela fecha a boca sobre o corpo do outro. Ela estabelece ou reestabelece um contato por meio do qual ela inverte os papéis: a criança que foi contida contém, por sua vez, o corpo que a continha. Mas ela não o encerra em si, muito pelo contrário; ela 0 mantém à sua frente simultaneamente. O movimento dos lábios que chupam não cessa de retomar a alternância de proximidade e de distanciamento, de penetração e de saída que orientou a descida desde o ventre até a saída do corpo, desse corpo novo finalmente prestes a se separar (NANCY, 2017, p.16)
Na primeira infância, "não importa tanto o que dizem as palavras, mas como dizemos as palavras" (HORTÉLIO; REYS, 2013, p.26). Cabe lembrar que antes de nascer os bebês são introduzidos no universo da língua porque estão nos pensamentos e nas palavras dos que o esperam (KAHN; BRULEY; BARBIERI, 2013, p.33). Depois que nascem, costumamos falar com os bebês, especialmente nos momentos de cuidado com o seu corpo, inventariando uma multiplicidade de sonoridades e formas de expressividade afetiva para sublinhar nosso vínculo. Além disso, as mães ou pessoas que cuidam do bebê, pela palavra, costumam também lhe dar informação: seu pai está chegando, a vovó Ihe trouxe um presente!

Assim, constatamos que a palavra está muito presente na vida dos bebês (KAHN; BRULEY; BARBIERI, 2019, p.34). Os estudos de Dumas, Bruley e Tourn (1988) reafirmam esse enunciado quando evidenciam a existência de dois tipos de palavras que habitam o universo infantil: as palavrascarícias e as palavras-rituais. As autoras afirmam que as palavras-carícias pertencem ao universo de ditos, falas, cantos e incisos melódicos que os adultos inventam para se comunicar com o bebê. São aquelas palavras sem sentido ou funcionalidade, bobagens livres que utilizamos para narrar afetos, com eles criar laços, abraços, encantos que, de modo geral, vêm acompanhadas de toque corporal e costumam ressoar diminutivos, sendo entoadas cara a cara. Enfim, pequenos improvisos que narram a alegria do convívio: meu tictic, gotigotiiiii, xuxuzinhooooooo, cudicudi. Nessas palavras, vivemos num idioma sem regras que no convívio criamos e, na intimidade dos encontros, vamos cada vez nos sentindo mais à vontade para embarcar nessa outra língua "que não sabíamos que sabíamos" (COUTO, 2011).

Porém, o "curioso é constatar que o que há de mais intraduzível de uma língua para outra são os fenômenos do som e da sonoridade" (BACHELARD, 1989 , p.46) pelos quais as crianças pequenas, desde bebês, se apropriam das complexas e plurais maneiras de ser de sua língua mãe. Além disso, 
constamos que a partir dos seis meses as crianças abandonam o prisma sonoro extenso que dispõem para se entregar ao exercício de brincar com os sons de sua língua, empreendendo diferentes trajetos para "abocanhá-los", isto é, tê-los em seu corpo.

Nesse sentido, Dumas, Bruley e Tourn (1988) destacam que o universo infantil também é alimentado pelas palavras-rituais. Fazendo parte do patrimônio oral de diferentes culturas essas palavras são aquelas que a memória armazenou e que pertencem a cultura de cada civilização. Tais palavras atraem para o discurso a literatura, a música e a dança com forma estruturada de linguagem, apresentando uma gramática específica. Representam um acercamento ao universo cultural de cada língua no qual as fronteiras entre oralidade e escrita, letrado e iletrado, recreação e conhecimento se cruzam e emergem de modo interdependente. No Brasil, o repertório de palavras-rituais é extenso. Podemos citar as canções de ninar, as parlendas, os brincos, as mnemônicas, os trava-línguas, as rimas, as trovas, os enigmas, as charadas, as adivinhações, as histórias cantadas, as lendas, as rodas de verso, as festas datalícias, os folguedos, etc.

As investigações de Gainza (1983), Fridmann (1988) e Lino (2005) narraram a entrega lúdica entre bebês e adultos nesta língua improvisada: cantos, proto-ritmos, palavras. $\mathrm{Na}$ maioria das vezes, conversas que os bebês e suas mães inventam "juntos", no aconchego de colos e carícias: "tudo começa ao acaso, ela [Jum, 6m] está com sono, pego no colo e vamos dançando. Invento na hora um canto em "boca chiusa". Ela canta comigo, como se soubesse o que nem mesmo eu sei onde vai dar, pura sintonia" (LINO, 2005). Aqui emerge a palavra sonora como aventura pelo encontro da partilha no qual ambos - bebê e adulto - se deixam tocar, entrando em ressonância. Neste instante, a palavra não quer in-formar nada, mas conjugar presença, ou melhor, vibrar o som do sentido e não o sentido do som (NANCY, 2007).

Tatuado na palavra temos sempre o som. Essa presença sonora que chega, comporta um ataque e incorpora uma tensão. Toca a palavra, pela escuta, provocando ressonância, este som do sentido (NANCY, 2007). Assim, o sentido vibra, expondo a coexistência entre ruído e música, entre corpo e mundo, entre singular e plural. Isto porque, o acontecimento sonoro não tem lugar, mas ocupa um espaço. Não tem um sentido a descobrir. Mas toca nossa pele pela existência. Segundo o filósofo francês Nancy (2013) o sentido se encontra no que acontece, ou no que nos acontece, no esforço que experimentamos ao habitar o mundo.

A palavra sonora produz ressonância em nosso corpo, carregando a música em seu estado de encontro, potência de linguagem em constante deslocamento, porque toca o corpo que sendo a única via de acesso sensível, marca coexistência. Nesse caso, a palavra sonora não precisa ser traduzida nem transferida porque o corpo é a ferramenta e a conclusão, o princípio e o fim, pulsão e expulsão, a partitura impressa e expressa. problema é a unidade do múltiplo (NANCY, 2013).

Ao sonoro cabe o privilégio de expor a ressonância, mais além da significação: o ruído assedia todo o corpo, o silêncio o aguça, o som arrebata sua forma, a música inaugura modos de ser no mundo. O sonoro acolhe o ruído, o silêncio, o som e a música sem separações. Ele é o sentido inteiro, sem reservas; não apenas um fenômeno acústico a decifrar. O sonoro faz tocar, porque ressonância, dilatação e reverberação. Mas há que mover-se para tocar, chegar ao com-tato, permitir esse toque pontual, vibratório, ressonância de sentidos (NANCY, 2013, p.12).

A palavra sonora é o atrito do corpo com o real que emerge da criança que experimenta o mundo como espaço e tempo do pensamento. Uma sensibilidade que se situa no espaço anterior à reflexão, porque não brota do conhecimento racional ou de reflexões mais elaboradas, mas flui nos tempos e espaços constituintes das materialidades experimentadas intencionalmente pelo corpo ao aderir ao mundo (MERLEAU-PONTY, 1980, p. 34).

A palavra sonora é um estado de conversação do corpo no mundo. Apesar de "volátil, volúvel, vaporosa, instável e invisível, a palavra falada 
pesa na boca e também nos ouvidos" (STOLF, 2011, p. 59). No corpo, a palavra ocupa espaço e solicita tempo, pois som do sentido singular e compartilhado no qual o gesto, o movimento, a dança, a música, a diversão, a alegria e a ludicidade se justapõem. Logo, a palavra sonora exige uma com versa:

\begin{abstract}
estar com (con), virar-se (versar) para - ou seja para fora do eu apenas. O verso da poesia e o verso da conversação estão relacionados apenas dessa forma, como um literal virar-se - na melhor das hipóteses, inesperadamente, em direção aos nossos muitos passados, presente, futuros, isto é, em direção a possibilidades, contingências, reconhecimentos, ininteligibilidades (CAGE, 2015, p.17).
\end{abstract}

Se a infância confere à palavra sonora o tempo e espaço de tocar o gesto poético, vale destacar que o sentido nunca está dado, se efetua no ofício indeterminado e imprevisível do brincar. No caminho entrepartido da palavra sonora, o gesto poético de fabular irrompe nas narrativas lúdicas que as crianças experimentam. Inúmeras vezes as mães se encantam ao compreender que as crianças querem saber como as bocas se abrem, se fecham e como contam coisas, cantam palavras, gritam, inventam comunicação. Logo, a palavra sonora é inventora potente de mundos. Ela pode te acolher ou pode te rechaçar. Nesse sentido, a palavra sonora tem na voz

essa marca, essa experiência, esses avatares que fazem com que aqueles que falam e aqueles que ouvem, aqueles que dão e aqueles que recebem, sejam sujeitos concretos, singulares e finitos, de carne e osso, e não apenas máquinas comunicativas (emissores e receptores de significados), ou máquinas cognitivas (codificadores e decodificadores de informação). A voz, então, seria como a face sensível da língua, essa que faz com que ela não seja apenas inteligível, que não esteja toda ela do lado do significado, que não seja apenas um instrumento eficaz e transparente de comunicação, que não seja apenas uma voz mecânica, sem nada por dentro (LARROSA, 2008)

A voz do cantador é também o seu corpo no corpo do outro. A palavra sonora é uma respiração que fala, canta, chora, narra. Ela traz no tempo os ritmos indivisíveis do corpo que habita o mundo, unidade de multiplicidade sempre em continuidade, sempre por fazer-se. No plano dos ritmos corporais a palavra sonora é o gesto de mediação entre corpo e mundo, uma passagem que contém em si própria a possibilidade de operar e não operar sentidos.

Portanto, feito partitura, o gesto poético da palavra sonora toca a pele de crianças e adultos para materializar a linguagem: suas feituras. Potência constitutiva do humano em seus trajetos coexistentes no mundo que não pretendem demarcar territórios, mas constituir narrativas. Um corpo que, encarnado, acolhe o movimento da ludicidade para conjugar a palavra sonora no fascínio e na fabulação dos encontros.

Destacar a palavra sonora como gesto poético intraduzível em sua potência e inoperosidade, é sublinhar na educação de bebês e crianças o poder de abertura à fabulação e ao ficcional que a palavra sonora pode ou não inaugurar. É constituir a disponibilidade educativa em autorizar ações arriscadas e contingentes a partir de ruídos, sons, silêncios e músicas, fragmentos do vivido que vão articulando aprendizagens que exigem o gesto de educar como gesto poético que promove e desafia a co-participação no tocar o mundo para produzi-lo na convivência. Mas antes, é enfrentar a inquietude pela potência - e impotência - de uma experiência de pensamento que nos instala no mundo comum e que está no centro das atuais disputas pelo sentido de humano por dizer respeito ao sentido entre o vivido e o vivível na tarefa de educar a partir da interrogação por quais saberes seriam necessários elaborar e compartilhar para uma convivência que permita responder ao projeto educacional do capitalismo cognitivo.

$\begin{aligned} \text { Muito antes de conhecimentos e } & \text { échicas e instrumentos de }\end{aligned}$ classificação de competências e avaliação de habilidades, educar implica intencionalmente ir ao encontro do grande enigma existencial que é a possibilidade de cotidianamente aprender a compartilhar experiências fundamentais da vida, como a empatia, o amor, o compromisso, o medo, o cuidado, o sentido da dignidade e da justiça, a morte. Talvez, tenhamos que revisar, no pensamento educacional, o antigo conceito de responsabilidade para 
enfrentarmos a evidência de que somos responsáveis não apenas por aquilo que sonhamos e fazemos, mas também por aquilo que participamos.

\section{Referências}

AGAMBEN, Giorgio. Ideia de Prosa. Lisboa: Cotovia, 1999.

AGAMBEN, Giorgio. Arte, Inoperatividade, Política. In: Crítica do Contemporâneo. Agamben. Marramao. Rancière. Sloterdijk. Política. Conferências Internacionais Serralves, 2007, p. 39-49. Disponível em: <https://www.serralves.pt/fotos/editor2/PDFs/CCCIS-2007-POLITICA-web.pdf> Acesso em: 21 mar. 2020

AGAMBEN, Giiorgio. Medios sin fin. Notas sobre la política. Valencia, España: Pre-Textos, 2010.

AGAMBEN, Giorgio. Infância e História: ensayo sobre la destrucción de la experiência. 5.ed. Adriana Hidalgo Editora: Buenos Aires, 2011.

AGAMBEN, Giorgio. O fogo e o relato: ensaios sobre criação, escrita, arte e livros. 1.ed. São Paulo: Boitempo, 2018.

AKOSCHKY, Judith. Escuchar, Cantar e Tocar. Compartir Experiencias Musicales em los Primeros Años. In: SOTO, Claudia; VIOLANTE, Rosa. Experiencias Estéticas em los Primeros Años. Buenos Aires: Paidós, 2016.

ANDRADE, Mário. Compêndio de História da Música. São Paulo: Eugênio Cupolo, 1929. (Exemplar de trabalhos e manuscritos de Mário de Andrade do Arquivo do Instituto de Estudos Brasileiros da Universidade de São Paulo).

ARENDT, Hannah. A condição humana. Trad. Roberto Raposo; revisão técnica e apresentação Adriano Correia. 12.ed. revisada. Rio de Janeiro: Forense Universitária, 2014.

ARENDT, Hannah. Entre o passado e o futuro. São Paulo: Editora Perspectiva, 2003, p. 221-247.

BACHELARD, Gaston. A chama de uma vela. São Paulo: Editora Bertrand Brasil, 1989.

BACHELARD, Gaston. A poética do devaneio. Tradução Antonio de Pádua Danesi. São Paulo: Martins Fontes, 1988.

BACHELARD, Gaston. Fragmentos de uma poética do fogo. São Paulo: Brasiliense, 1990.

BACHELARD, Gaston. Le racionalisme appliqué. Paris: PUF, 1966.

BARROS, Manoel de. Do menino do mato. Rio de Janeiro: Objetiva, 2015.

CAGE, John. Musicage: palavras. John Cage em conversação com Joan Retallack. Rio de Janeiro: Numa, 2015.

COUTO, Mia. E se Obama fosse africano? e outras intervenções. São Paulo: Companhia das Letras, 2011.
DUMAS, Philippe; BRULEY, Marie Claire; TOURN, Lya. Enfantines: Jouer, Parler avec le Bébé. 1.ed. Paris: EDL, 1988.

FRIDMANN, Ruth. El nacimiento e la inteligencia musical. 1.ed.Buenos Aires: Editorial Guadalupe, 1988.

GAINZA, Violeta Hemsy de. La improvisación musical. 1.ed. Ricordi: Buenos Aires, 1983.

GARCÈS, Marina. Nueva ilustración radical. Barcelona: Editorial Anagrama, 2017.

HORTÉLIO, Lydia. Jornada de Amor às Infâncias II. Madre Tierra: Comunidade Verde Aprendente \& Residência Criadora: experiências em Pedagogias Poéticas com Lydia Hortélio. Curso Ministrado de 6 a 8 de março, Porto Alegre, 2020.

HORTÉLIO, Lydia. Uma experiência em educação. Lisboa: Livros Horizonte, 1982.

HORTÉLIO, Lydia; REYS, Yolanda. No caminho da leitura: a importância das palavras, das narrativas e do brincar na primeira infância. In: PRADES, Dolores (Editora). Crianças e jovens no século XXI: leitores e leituras. São Paulo: Livros da Matriz, 2013. Disponível em:

<https://issuu.com/revistaemilia/docs/crian_as_e_jov ens_no_s_culo_xxi_->. Acesso em: 20 mar. 2020

KAHN, Isabel; BRULEY, Marie-Claire; BARBIERI, Stela. Infâncias e histórias: cantigas de ninar, gestos, imagens, ritmos, transmissões culturais na infância. In: PRADES, Dolores (Editora). Crianças e jovens no século XXI: leitores e leituras. São Paulo: Livros da Matriz, 2013. Disponível em: <https://issuu.com/revistaemilia/docs/crian_as_e_jov ens_no_s_culo_xxi_->. Acesso em: 19 mar. 2020

LARROSA, Jorge. Aprender de oído. Intervenção no Ciclo de Debates Liquidación por derribo: leer, escribir y pensar en la Universidad - La Central. Barcelona, abril - 2008. Disponivel em: $<$ http://dueloliterae.blogspot.com/2013/12/aprenderde-oido-por-jorge-larrosa.html>. Acesso em: 19 mar. 2020

LARROSA, Jorge. Lenguaje y educación. Rev. Bras. Educ. [online]. 2001, n.16, pp.68-80.

LINO, Dulcimarta Lemos. Experiências PoéticoSonoras na Infância. Vídeo. São Leopoldo: UNISINOS, 2005.

LINO, Dulcimarta Lemos. Barulhar: a escuta sensível da música nas culturas da infância. Tese (Doutorado em Educação) Faculdade de Educação, Universidade Federal do Rio Grande do Sul, Porto Alegre, 2008.

LÓPEZ, Maria Emilia. Breve ensaio sobre a palavra poética e a proteção simbólica da infância. In: PRADES, Dolores; MEDRANO, Sandra (Coords). Seminário Internacional 2018: Arte, palavra e leitura na primeira infância. 1.ed. São Paulo: Instituto Emília, 2019. Disponível em: <https://www.comunidadeeducativa.org.br/wpcontent/uploads/2019/04/seminario-apl-final.pdf>. Acesso em: 19 mar. 2020 
MACHADO, Silvia de Ambrosis Pinheiro Machado. Canção de Ninar Brasileira: Aproximações. São Paulo: Editora da Universidade de São Paulo, 2017.

MELO, Verissímo. Folclore Infantil. São Paulo: Editora Itatiaia, 1985.

MERLEAU-PONTY, Maurice. Fenomenologia da percepção. São Paulo: Martins Fontes, 1999.

MERLEAU-PONTY, Maurice. Signos. Tradução de Maria Ermantina Galvão Gomes Pereira. São Paulo: Martins Fontes, 1991.

NANCY, Jean Luc. Política e/ou Politica. ALEA. Rio de Janeiro, vol. 17, n.1, p. 166-178, jan-jun, 2015. Disponível em: <http://www.scielo.br/scielo.php?script=sci_arttext\&pi $\mathrm{d}=\mathrm{S} 1517-106 \mathrm{X} 2015000100166>$. Acesso em: 19 mar. 2020

NANCY, Jean-Luc. A la escucha. Buenos Aires: Amorrortu, 2007. Colección Nómadas.

NANCY, Jean-Luc. Archivida. Del Sintiente y del sentido. 1 ed. Ciudad Autonoma de Buenos Aires: Quadrata, 2013. Colección Contemporaneos.

NANCY, Jean-Luc. El arte hoy. Prólogo de Daniel Alvaro. Ciudad Autónoma de Buenos Aires: Prometeo Libros, 2014.

NANCY, Jean-Luc. El olvido de la filosofia. Traducción Pablo Perera Velamazán. Madrid: Arena Libros, 2003.

NANCY, Jean-Luc. Fazer, a poesia. ALEA: Rio de Janeiro, v.15, n.2, p.414-422, jul-dez 2013a. Disponível em: $<\mathrm{http}$ ://www.scielo.br/pdf/alea/v15n2/10.pdf>. Acesso em 10 jun. 2019.

NANCY, Jean-Luc. Que significa partir? Buenos Aires: Capital Intelectual, 2016.

NANCY, Jean-Luc. Ser singular plural. Madrid: Arena Libros, 2006.

NANCY, Jean-Luc. La posibilidad de un mundo. Diálogo con Pierre-Philippe Jandin. Traducción de Isidro Herrera. Madrid: Arena Libros, 2019.

RICHTER, Sandra Regina Simonis; BERLE, Simone. A pedagogia como gesto poético. Educação \& Realidade, Porto Alegre, v. 40, n. 4, p. 1027-1043, out./dez. 2015.

RODRIGUES, Joao Barbosa. Poranduba Amazonense. Rio de Janeiro: Typ. De G. Leuzinger, 1890.

SKLIAR, Carlos. Dar infancia a la niñez. Entrevista concedida a Carolina Duek. El Psitio / Cultura y Educación em 4 de Dez. 2018. Disponível em: $<$ http://www.elpsitio.com.ar/Noticias/NoticiaMuestra.as p?ld=2508> Acesso em 10 dez. 2018.

STOLF, Maria Raquel da Silva. Entre a palavra pênsil e a escuta porosa: [investigações sob proposições sonoras]. 2011. 324 p. Tese. Doutorado. Universidade Federal do Rio Grande do Sul, Porto Alegre. Disponível <https://lume.ufrgs.br/handle/10183/34774> Acesso em mar. 2020

VELOSO, Caetano. Velô. São Paulo: Phillips Records, 1984.

VIEIRA, Ana Paula Leite. Cecília Meireles e a educação da infância pelo folclore. 2013. 182. Dissertação (Mestrado) Universidade Federal Fluminense, Instituto de Ciências Humanas e Filosofia, Departamento de História, Niterói, 2013. 
COMO CITAR ESSE ARTIGO

LINO, Dulcimarta Lemos; RICHTER, Sandra Regina Simonis. FEITO PARTITURA: PALAVRA SONORA COMO GESTO POÉTICO DE EDUCAR. Signo, Santa Cruz do Sul, v. 45, n. 83, p. 2-16, set. 2020. ISSN 1982-2014. Disponível em: <https://online.unisc.br/seer/index.php/signo/article/view/14948>. Acesso em:. doi:https://doi.org/10.17058/signo.v45i83.14948. 